\title{
A PERCEPÇÃO DA QUALIDADE NO SETOR HOTELEIRO DE SANTA MARIA: CLIENTES VERSUS GESTORES
}

\section{Paulo Edivan Rezende Gomes ${ }^{1}$, Edson Machado Wollmann², Leandro Dorneles dos Santos ${ }^{3}$}

RESUMO: A qualidade pode ser percebida de diferentes maneiras quando se avalia um produto/serviço, seja na visão do cliente ou na concepção do gestor. Entender estas diferenças pode possibilitar melhorias significativas na qualidade do produto/serviço. Por isso, esta pesquisa teve como objetivo entender a percepção da qualidade no setor hoteleiro de Santa Maria, na visão do cliente e na visão dos gestores. 0 método utilizado caracterizou a pesquisa como descritiva, a partir de uma pesquisa de campo com aplicação de questionários junto a clientes e gestores de hotéis da cidade de Santa Maria, RS. A análise dos dados deu-se de maneira quantitativa, utilizando técnicas estatísticas para análise. Os principais resultados revelaram que o cliente e o gestor têm diferenças no modo de perceber a qualidade, uma vez que os clientes se preocupam com o conforto e os gestores com todos os elementos, inclusive com fatores secundários para os clientes.

Palavras-chave: Percepção da qualidade. Setor hoteleiro. Gestão da qualidade. Cliente. Gestor.

Submissão: $16 / 03 / 2020$

Aceite: $12 / 11 / 2020$

DOI: $10.47591 / 2674-9203.2020 \mathrm{v} 2 \mathrm{n} 1 . \operatorname{art} 2-17-28$

\section{c) (7) (8)}

Este trabalho está licenciado com uma Licença Creative Commons Atribuição-NãoComercial 4.0 Internacional.

\footnotetext{
${ }^{1}$ Bacharel em Administração pela Faculdade Integrada de Santa Maria - FISMA. E-mail: pauloedivangomes@hotmail.com

${ }^{2}$ Bacharel em Administração pela Faculdade Integrada de Santa Maria - FISMA. E-mail: edsonmw81@gmail.com

${ }^{3}$ Bacharel em Administração. Mestre em Gestão Estratégica de Organizações pela Universidade Regional Integrada - URI Santo Ângelo. E-mail: Leandro.dorneles@ fisma.com.br
} 


\section{INTRODUÇÃO}

Nos últimos anos, a qualidade vem ganhando um destaque cada vez maior dentro do mercado de consumo, tanto no que se refere a produtos como a serviços. Para Defeo e Juran (2015, p. 1), "bens e serviços de qualidade superior geram resultados financeiros sustentáveis, pois ser superiores aos dos concorrentes os tornam vendáveis".

De acordo com Paladini (2012), o contexto mudou muito nos últimos anos em relação a qualidade, pois acreditava-se que uma empresa do ramo de serviços não poderia produzir qualidade. No entanto, além da ampliação do mercado e da facilidade com a qual uma empresa de serviços pode ser aberta - em comparação com uma indústria, o que fez com que a concorrência aumentasse, tornando necessárias preocupações com tecnologia, aporte de capital, estudo, análise e pesquisa etc. -, os consumidores aprenderam a ter mais objetividade para avaliar a qualidade de serviços. (PALADINI, 2012).

Sendo a qualidade percebida pelo cliente, isto é, algo que depende do julgamento que cada indivíduo tem sobre qualidade, no setor de serviços, destacamse os hotéis, que estão sempre inovando, uma vez que a competitividade nesse ramo é acirrada pela quantidade de empresas que oferecem este tipo de serviço.

Neste sentido, nota-se que o ramo de serviços ganhou importância a partir da década de 1960, na era pós-industrial, quando os serviços se tornaram tão importantes quanto os produtos, expandido o setor terciário. (LICKFELD, 2000). Segundo o Instituto Brasileiro de Geografia e Estatística (IBGE), os serviços vêm ganhando destaque na economia mundial, devido a alguns fatores, como a geração de renda e emprego, bem como a contribuição econômica para os países, tanto que os países com maior índice de desenvolvimento baseiam sua economia no setor de serviços. (IBGE, 2002).

Neste universo, destacam-se os serviços de hotelaria. De acordo com Flores (2002), uma organização não deve se preocupar somente com a hospedagem, mas também com a preparação no pedido do cliente, o ambiente que irá encontrar, os serviços que oferecerá , o bem-estar dele e a pós hospedagem, pois quando aquele cliente retornar, irá com certeza para o hotel que o fez sentir-se bem.

Neste sentido, o que se pretendeu resolver com esta pesquisa foi: Qual a percepção da qualidade nos hotéis de Santa Maria, na visão dos clientes e na visão dos gestores? Assim, o objetivo do estudo foi entender a percepção da qualidade no setor hoteleiro de Santa Maria, RS, na visão dos clientes e na visão dos gestores.

Este trabalho justificou-se por buscar entender as divergências e convergências desses públicos, para ajustar e melhorar as decisões tomadas pelos gestores no setor. Para os pesquisadores, foi uma excelente oportunidade de realizar uma coleta de dados e sua posterior análise, desenvolvendo, na prática, os estudos realizados em sala de aula. Para o setor hoteleiro, acredita-se que os resultados possam proporcionar mais segurança na tomada de decisão dos gestores a partir do conhecimento das lacunas entre as percepções. 


\section{REVISÃO TEÓRICA}

\subsection{O SETOR HOTELEIRO E A SATISFACÃO DO CLIENTE}

A prestação de serviços do segmento dos hotéis merece um grande destaque pela geração de empregos, pois segundo dados do SEBRAE, em 2005 o setor foi responsável por gerar cerca de 500 mil empregos diretos e $600 \mathrm{mil}$ indiretos, o que tem um impacto objetivo no desenvolvimento do país. (GORINI; MENDES, 2005).

Entretanto, alguns problemas são enfrentados por esse setor no que tange à mão-de-obra qualificada, aos altos custos com rotatividade de pessoal e à necessidade de alto índice de lucratividade (MARQUES, 2003), o que dificulta uma melhora maior no setor, uma vez que o treinamento é ineficiente por causa das razões e problemas que são atreladas ao setor. (GIANESI; CORRÊA, 2006). Mesmo assim, o setor mantém-se firme graças ao seu principal objetivo, que é atender o cliente com qualidade. (MARQUES, 2003).

O setor busca um equilíbrio para alcançar a satisfação do cliente, ora flexibilizando seu trabalho, ora inovando (SOUZA; CASTRO-LUCAS, 2007), pois o setor hoteleiro é um grande exemplo do setor terciário, já que a importância da satisfação do cliente é ponto fundamental para fomentar o crescimento do setor. (VIEIRA, 2002).

Kotler e Keller (2006) definem a satisfação como uma sensação boa por parte dos clientes, que os fazem querer experimentar mais vezes aquele atendimento que lhes proporcionou prazer. Pizarn e Ellis (1999) comentam que existem o cliente insatisfeito, que é aquele que não teve suas expectativas superadas e não recomenda o atendimento a ninguém, pelo contrário propaga mal dizeres; e o cliente satisfeito, que muitas vezes tem suas expectativas superadas, mas raramente repassa aos conhecidos, e retorna ao local ou volta a utilizar o serviço.

Ainda sobre as expectativas dos clientes, Oliver (1980) afirma que o quadro de satisfação do cliente serve como referência para todo o setor e, dessa forma, os mesmos devem buscar realizar pesquisas com os clientes, para sempre estar melhorando os processos para aumentar a qualidade na prestação de serviços.

Segundo Sheth, Mittal e Newman (2001), o desconforto sentido, tanto físico como emocional, afastam os clientes do prestador de serviços. Mas caso aconteça o contrário, a qualidade percebida serve com um impulsionador da organização frente aos seus concorrentes, levando a organização a um patamar de referência para os indivíduos. (TINOCO, 2006).

\subsection{GESTORES INTRAEMPREENDEDORES E QUALIDADE}

0 setor hoteleiro tem grande crescimento no mercado da prestação de serviços e os gestores desse setor têm grande participação, uma vez que dedicam muitas horas durante toda a semana para manter o local em funcionamento (GRAY, 2002). De acordo com Gray (2002), o gestor precisa ter características específicas para o negócio expandir como habilidades no que tange à liderança e à capacidade gerencial de pessoas e finanças. 
Dessa forma, conforme a Associação Brasileira da Indústria Hoteleira $(\mathrm{ABIH})$, os gestores que apresentam essas qualidades são fontes de transformação e crescimento, contemplando vantagens competitivas para as organizações que comandam, sendo então, importantes para o setor hoteleiro. (ABIH, 2007).

Outra questão a ser considerada é que o tamanho da organização e a preparação do gestor afetam diretamente o desempenho do mesmo, ou seja, precisa ser analisado o quanto é capacitado o gestor hoteleiro. (MORRISON; THOMAS, 1999). Destaca-se que, neste sentido, Bulut e Alpkan (2006) defendem a autonomia do gestor em propor melhorias constantes ao estabelecimento para melhorar a qualidade do ambiente, assim como o atendimento e os demais setores do hotel.

Em outra frente, Rodrigues, Leal e Hargreaves (1997) afirmam que a qualidade no atendimento e na prestação de serviços é um diferencial no mercado competitivo do qual os hotéis fazem parte, pois o público que utiliza esse setor está cada vez mais exigente e busca qualidade, mesmo que seja necessário pagar um valor maior por isso.

Contudo, pode-se perceber que a qualidade se torna um dos mais importantes fatores dentro da prestação de serviços, uma vez que auxilia no fato do cliente não se decepcionar com o que está sendo prestado (ALMEIDA, 2001). Isso ocorre por que os hotéis estão preocupados em oferecer aquilo que é prometido ao cliente, e o cliente preocupado em ter suas necessidades sanadas. (PARASURAMAN; ZEITHAML; BERRY, 1985).

No ramo de hotelaria, fala-se que a prestação de serviços envolve atividades de desempenho tangível, ou seja, apesar de não tocar no serviço, o cliente tem contato direto com o indivíduo que presta o serviço. (LOVELOCK; GUMMESSON, 2004), pois os resultados são concretos, como por exemplo, dormir bem à noite no hotel e acordar bem disposto no outro dia. Logo, os serviços são intangíveis, mas os resultados são perceptíveis.

Nesse sentido, o serviço de hotelaria deve se preocupar com a demanda a qual suporta, para poder ofertar um excelente serviço com extrema qualidade, podendo individualizar os serviços prestados em torno de determinados públicos, para aumentar a possibilidade de sucesso. (SERSON, 2000).

\section{MÉTODO}

A pesquisa consiste em encontrar respostas aos problemas propostos ao contexto atual (GIL, 2008) e, sendo assim, a mesma pode ser classificada quanto à: natureza, modalidade de pesquisa, abordagem do problema e pelos procedimentos técnicos.

Quanto à natureza, a pesquisa caracteriza-se como aplicada, uma vez que se buscou analisar a situação dos públicos envolvidos na pesquisa com relação à percepção de qualidade (GIL, 2008). No que diz respeito à modalidade de pesquisa, a mesma foi realizada seguindo os critérios da descrição, pois buscou-se entender a percepção dos clientes e dos gestores frente aos serviços hoteleiros da cidade de Santa Maria, RS. (MARCONI; LAKATOS, 2007).

A abordagem foi quantitativa, tendo sido utilizados questionários objetivos com respostas para serem assinaladas, pois "o enfoque quantitativo vale-se do levantamento de dados para provar hipóteses baseadas na medida numérica e da 
análise estatística para estabelecer padrões de comportamento". (MARCONI; LAKATOS, 2007, p. 285).

Quanto aos métodos de investigação, este estudo foi ao encontro do conceito de pesquisa de campo, tal como conceituado por Gil (2008), pelo fato de o pesquisador ir aos hotéis da cidade para a pesquisa ser realizada.

A atividade de pesquisa teve como foco de estudo os clientes, usuários do serviço de hotelaria, e os gestores de 19 hotéis da cidade de Santa Maria, RS. A amostragem considerada foi por conveniência, sendo que não se tinha um número absoluto de participantes que iriam responder aos questionários e, segundo Lakatos e Marconi (2007), conveniência é quando a seleção das unidades amostrais é deixada a cargo do entrevistador, não tendo uma quantidade especificada.

Dessa forma, o instrumento de coleta foi um questionário com 14 questões elaboradas com o objetivo de viabilizar a compreensão acerca da percepção dos respondentes sobre alguns aspectos, como: a localização do hotel, o preço, o ambiente, o conforto, a entrada de animais de estimação, a agilidade, o atendimento, as refeições, o tamanho do quarto, a segurança, a tecnologia e as áreas de convivência. Dessa forma, foram aplicadas as mesmas questões tanto para clientes quanto para gestores, com padrões de resposta em escalas do tipo Likert (Discordo totalmente, Discordo parcialmente, Indiferente, Concordo parcialmente, Concordo totalmente). Ainda, as duas questões iniciais indagaram sobre a relação com o hotel e de qual hotel está sendo respondido o questionário.

Após a coleta de dados, foram registrados os resultados no Formulário Google, a fim de gerar a tabulação dos mesmos, agilizando e facilitando as análises dos resultados.

O estudo foi dividido por etapas, sendo que a primeira foi a aplicação dos questionários nos meses de abril a julho do primeiro semestre de 2018, quando foram respondidos e validados 96 questionários. No mês de agosto foi feita a análise das respostas, e em novembro do mesmo ano foi finalizada a pesquisa.

\section{RESULTADOS}

Nesta parte são apresentados e discutidos os resultados obtidos com a realização da pesquisa, trazendo em sequência a resposta da percepção de qualidade dos clientes e dos gestores, por meio do estabelecimento de um paralelo entre estas informações.

A primeira questão buscou identificar a ligação do entrevistado com o hotel, enquanto que a segunda questão identificou qual hotel estava sendo avaliado nas respostas.

Dos 96 respondentes, 8 identificaram-se como gestores dos hotéis (dos 19 selecionados para o estudo) e 88 se declararam clientes. Sendo assim, apenas $42 \%$ dos gestores de hotéis responderam à pesquisa, e em média 4,5 clientes por hotel. Isso demonstra o quão difícil é a acessibilidade à gerência desses locais e aos clientes de uma forma geral, sendo que estes possuíam como justificativa o fato de estarem pernoitando na cidade. 
Na terceira questão, perguntou-se a qual hotel o cliente ou gestor pertencia, e obteve-se os seguintes resultados 1 : 21 (21,9\%) respondentes, pertenciam ao Hotel A, $19(19,8 \%)$ pertenciam ao Hotel B, $18(18,8 \%)$ respondentes pertenciam ao Hotel C, 13 (13,5\%) pertenciam ao Hotel D, 11 (11,5\%) pertenciam ao Hotel E, 9 (9,4\%) pertenciam ao Hotel $\mathrm{F}$ e, 5 (5,2\%) pertenciam ao Hotel G. Os dados mostram que existiu um certo equilíbrio entre o número de respondentes dos hotéis $\mathrm{A}, \mathrm{B}$ e $\mathrm{C}$, e também entre os hotéis $\mathrm{D}, \mathrm{E}$ e F. Destaca-se que estas três primeiras questões não foram numeradas no instrumento de coleta, já que buscaram categorizar os respondentes.

Na Questão 1, os respondentes foram questionados quanto à influência da localização do hotel para sua escolha, e as respostas dos clientes e gestores estão ilustradas a seguir, nos Gráficos 1 e 2.

Gráfico 1 - Influência da localização - Cliente

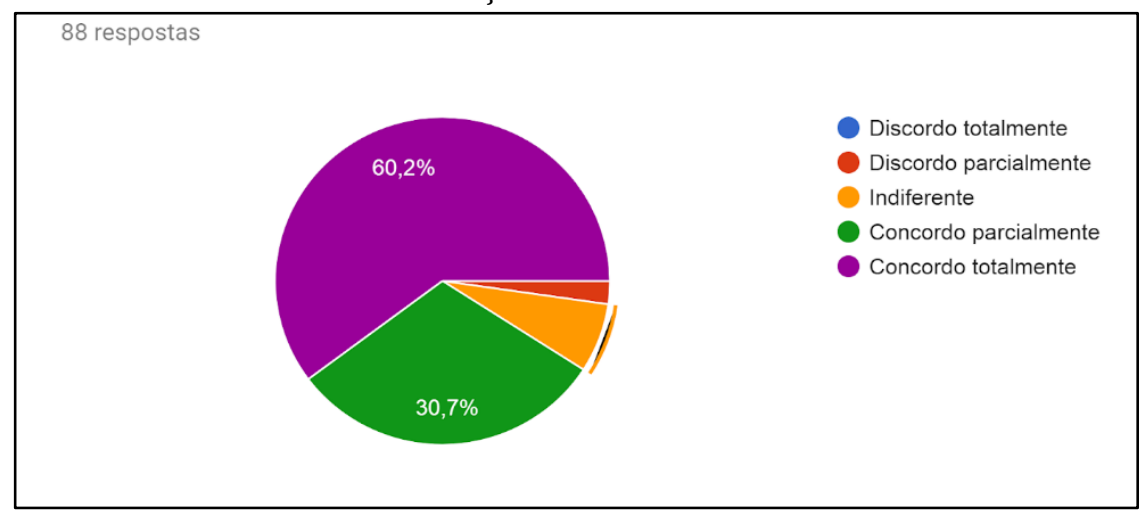

Fonte: dados da pesquisa (2018).

Gráfico 2 - Influência da localização - Gestor

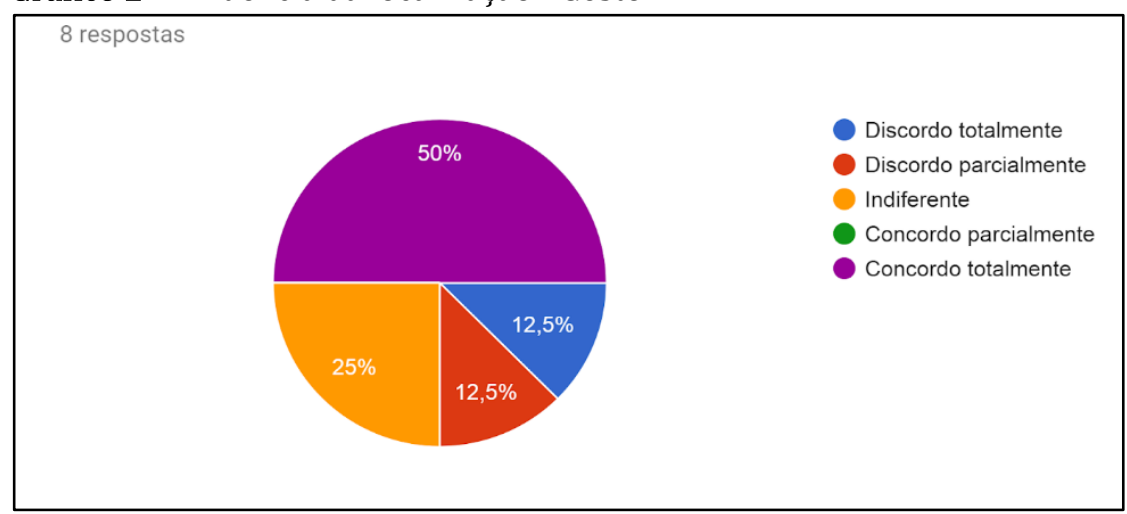

Fonte: dados da pesquisa (2018).

Para os clientes, $80,9 \%$ concordaram total ou parcialmente que a localização é um fator importante na hora de escolher o hotel, e 50\% dos gestores concordam totalmente que a localização influencia, dessa forma percebe-se que metade dos gestores respondentes têm uma visão errônea quanto a esse quesito, uma vez que $25 \%$ responderam que é indiferente e $25 \%$ discordam parcial ou totalmente que esse é um influenciador direto de escolha.

\footnotetext{
${ }^{1}$ Ressalta-se que, por questões de confidencialidade, os nomes dos hotéis foram suprimidos deste trabalho.
} 
$\mathrm{Na}$ questão 2, os participantes responderam sobre o fato de o preço ser compatível com o atendimento recebido e as respostas dos clientes e gestores foram parecidas. Quando perguntados sobre a relação entre o preço cobrado e o atendimento recebido/ofertado, clientes e gestores tiveram percepções parecidas, sendo que $86,4 \%$ dos clientes concordaram total ou parcialmente, corroborando com Kotler e Keller (2006), que afirmam que quanto maior o valor real, maior valor deve haver agregado na prestação do serviço. Já para os gestores, 87,5\% concordaram parcial ou totalmente com essa afirmação.

$\mathrm{Na}$ Questão 3 foi feita a seguinte afirmação: "O ambiente limpo favorece a imagem do hotel". As respostas dos clientes e dos gestores, quanto à concordância com esta afirmação, são apresentadas nos Gráficos 3 e 4.

Gráfico 3 - Limpeza do ambiente - Clientes

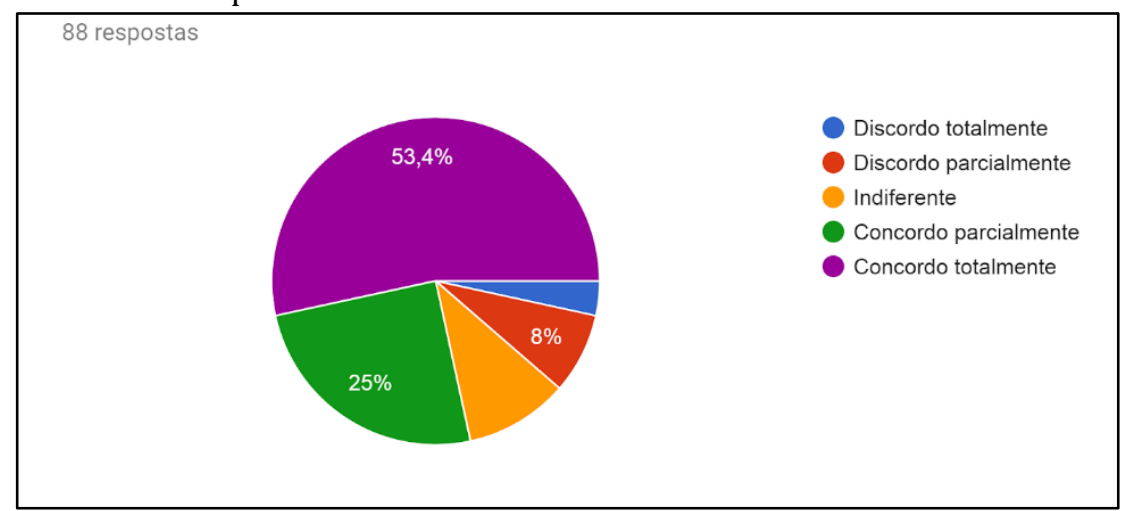

Fonte: dados da pesquisa (2018).

Gráfico 4 - Limpeza do ambiente - Gestores

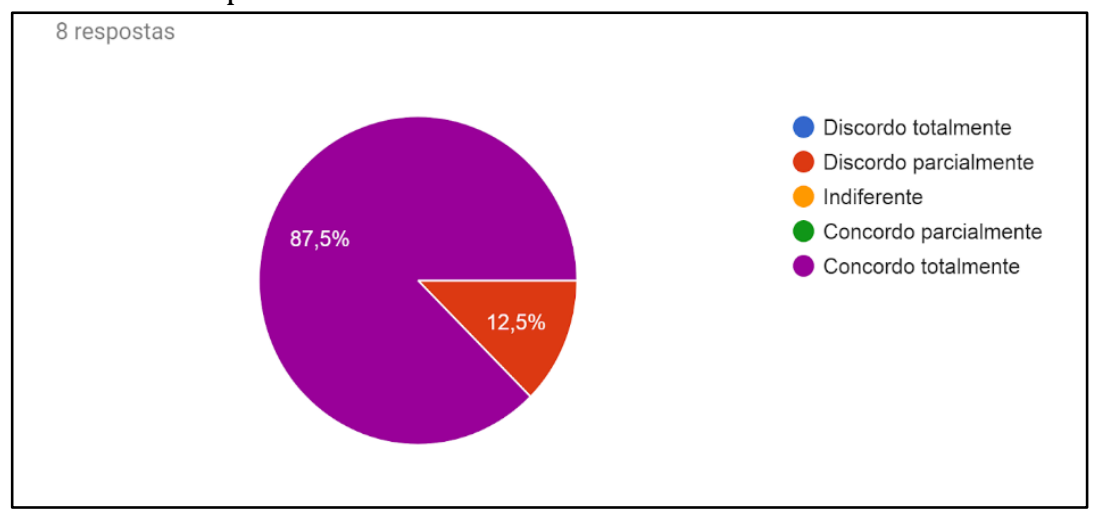

Fonte: dados da pesquisa (2018).

Quanto à limpeza do ambiente, os gestores mostram-se mais preocupados que os clientes, uma vez que $87,5 \%$ dos respondentes concordam totalmente que esse é um fator importante no que tange à qualidade da prestação do serviço. 78,4\% dos respondentes clientes também concordam total ou parcialmente que a limpeza favorece na escolha pelo hotel.

A Questão 4 foi sobre a preocupação do hotel com o conforto do cliente. Nota-se que os respondentes divergem sobre esse questionamento, já que apenas $26,1 \%$ dos clientes concordam totalmente que o hotel se preocupa com o seu conforto, e 15,9\% discordam parcialmente dessa preocupação, sendo que 87,5\% dos gestores concordam totalmente que se preocupam com o conforto dos clientes e o 
restante, $12,5 \%$ concordam parcialmente com essa afirmativa. Sendo assim, entende-se que alguns clientes se sentem desconfortáveis com o ambiente. Essa condição, segundo Solomon e Stuart (2003), faz com que o cliente nunca mais retorne ao local, já que o conforto é um fator determinante.

A Questão 5 envolve a entrada de animais de estimação nos locais, e isso sempre gera algum desconforto, já que alguns ambientes proíbem a entrada. Dessa forma, em relação aos clientes, 40,9\% são indiferentes quanto à entrada dos animais no hotel e 20,5\% discordam totalmente, isto é, já tiveram algum problema relacionado a essa restrição que alguns hotéis tem. Já quanto aos gestores, 50\% são indiferentes quanto à entrada de animais de estimação e 37,5\% concordam totalmente em aceitar animais de estimação, pois acreditam que é um diferencial competitivo e sinal de qualidade para ser escolhido pelos clientes.

Na Questão 6 indaga-se se a agilidade é um fator importante para a escolha do hotel. As respostas dos clientes e gestores seguem nos Gráficos 5 e 6.

Gráfico 5 - Agilidade - Clientes

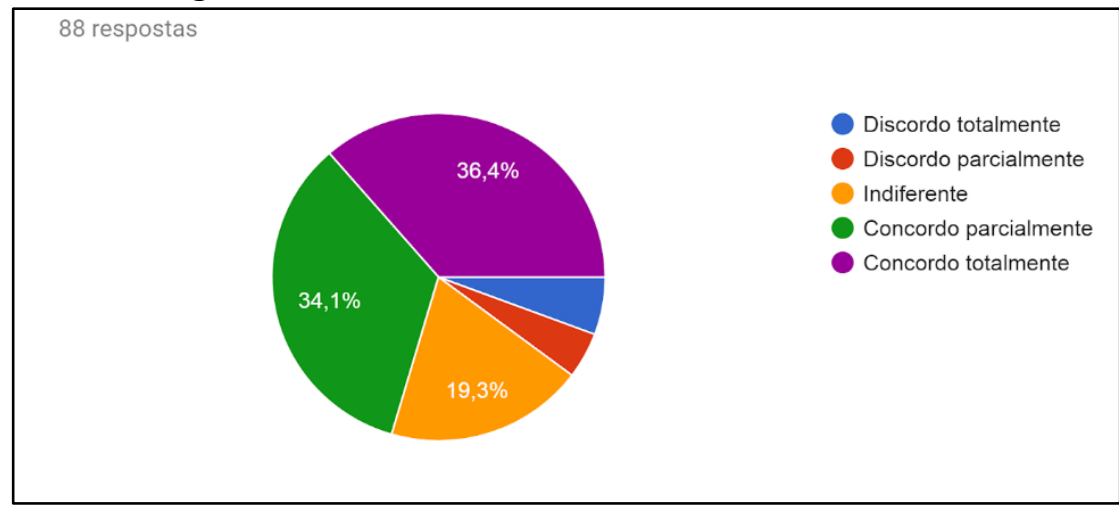

Fonte: dados da pesquisa (2018).

Gráfico 6 - Agilidade - Gestores

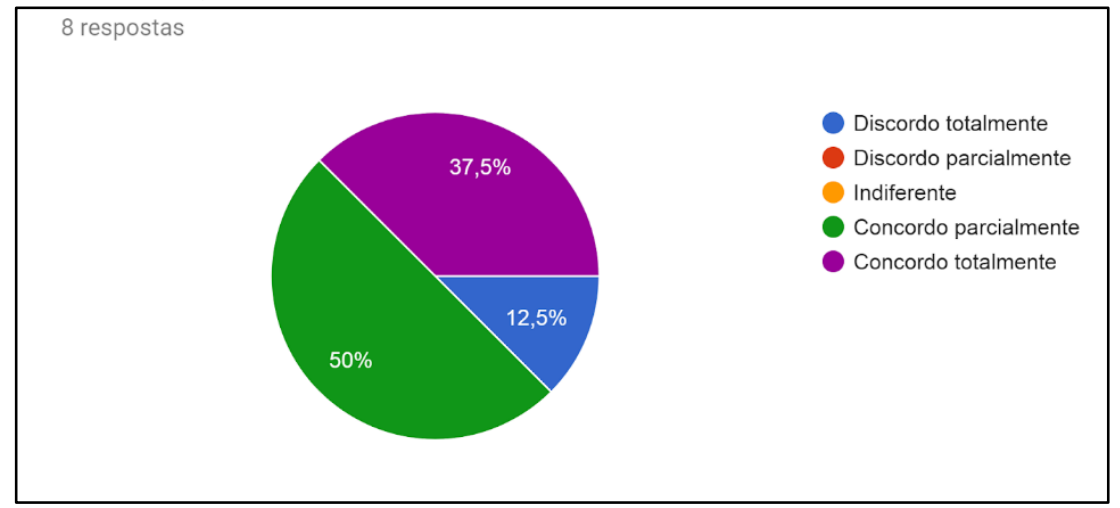

Fonte: dados da pesquisa (2018).

Percebe-se que os clientes e os gestores têm a mesma percepção no que se refere à questão da agilidade, já que 70,5\% dos clientes concordam total ou parcialmente que um trabalho rápido é bem aceito por eles. Já $87,5 \%$ dos gestores concordam parcial ou totalmente que esse fator é decisivo à escolha do hotel. Dessa forma, percebe-se que os gestores buscam a rapidez como um fator de qualidade a ser considerado pelo cliente. 
A Questão 7 faz uma reflexão sobre o atendimento ser a primeira impressão que fica do local e da prestação de serviço, assim como Serson (2000) reflete em seus estudos que cada cliente deseja ser atendido de alguma forma.

Para 74,2\% dos clientes, a primeira impressão sobre o hotel é marcada logo no atendimento, pois concordam total ou parcialmente. Para 87,5\% dos gestores que concordam parcial ou totalmente, esse é um fator muito importante, já que o primeiro contato direto entre hotel e cliente acontece no atendimento.

A Questão 8 fala sobre alimentação como um diferencial de qualidade. Desse fator, 31,8\% dos clientes são indiferentes quanto à refeição servida e a 11,4\% não se aplica, já que buscam somente o pernoite. Já para os gestores, esse fator é importante, uma vez que 87,5\% concordam totalmente ser um diferencial para quem busca ter qualidade na sua organização. Isso mostra outra afronta entre os respondentes, sendo que os gestores se preocupam com fatores secundários em relação à percepção do cliente.

A Questão 9 remete a um ponto importante que tem referência direta com o conforto do cliente, que é o tamanho do quarto. Neste quesito, clientes e gestores pensam de formas parecidas, já que $63,7 \%$ dos clientes ligam conforto com tamanho do quarto. Mas entre os gestores essa preocupação é muito grande, sendo que $100 \%$ dizem concordar parcial ou totalmente com essa afirmação. Isso demonstra que o conforto atrelado ao tamanho do ambiente faz parte das preocupações diárias do gestor, assim como apontado nos estudos de Kotler e Keller (2006), que afirmam que o conforto é o fator de maior relevância para ganhar o cliente no mercado competitivo.

A Questão 10 indagou os clientes e os gestores sobre o fator segurança. $62,5 \%$ dos clientes concordam parcialmente que esse é um fator a ser considerado na escolha do hotel. Os gestores concordam totalmente com essa afirmação (75\%), corroborando os estudos de Maslow (1972), que aborda que os fatores de segurança são importantes para o indivíduo.

$\mathrm{Na}$ Questão 11, questionou-se se a tecnologia oferecida pelo hotel (como Wi-fi, TVs por assinatura, entre outros) é importante para a escolha do hotel. Percebeu-se que este fator não tem tanta importância para ambas as partes, já que $22,7 \%$ dos clientes são indiferentes quanto à tecnologia oferecida e 39,8\% concordam parcialmente que é importante. Entre os gestores existe uma preocupação maior, mas também não há tanta divergência dos clientes, pois 12,5\% são indiferentes e 50\% concordam parcialmente que é importante a tecnologia como um fator decisivo para a escolha.

A Questão 12 relaciona expectativa com espaço da área de lazer, o que demonstra uma disparidade de pensamentos entre clientes e gestores, pois percebese que para 35,2\% o espaço de lazer é indiferente, como mostra o Gráfico 7, ou seja, não é esse fator que será decisivo para retornar ao hotel. Já 87,5\% dos gestores concordam total ou parcialmente que esse fator decide a volta do cliente, como mostra o Gráfico 8. 
Gráfico 7 - Expectativa x área de lazer - Clientes

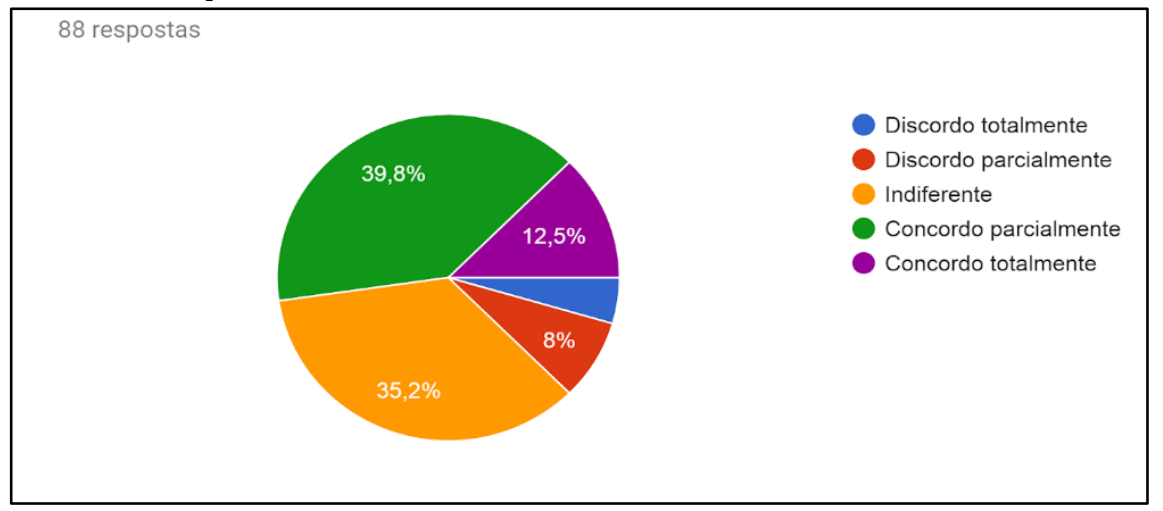

Fonte: dados da pesquisa (2018).

Gráfico 8 - Expectativa x área de lazer - Gestor

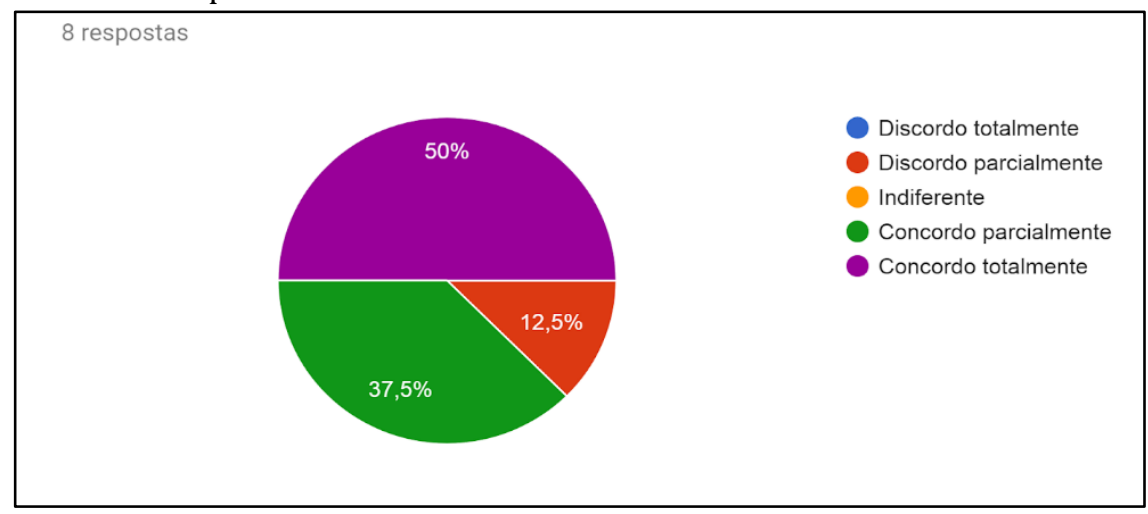

Fonte: dados da pesquisa (2018).

A questão 13 é sobre a área de convivência oferecida pelos hotéis da cidade, e nesse ponto mostra-se mais uma vez que os gestores se preocupam com fatores desnecessários, uma vez que $42 \%$ são indiferentes quanto ao hotel possuir tal área. Enquanto para os gestores esse ponto é importante, já que 75\% concordam parcial ou totalmente que esse fator será decisivo para a escolha do cliente, aderindo maior conforto e qualidade a estadia desses.

A Questão 14 mostra alguns exemplos de espaço de convivência, e pergunta aos clientes e gestores se os mesmos consideram importantes para a escolha do hotel. Entre os clientes estes espaços são indiferentes para escolha do hotel, tendo como um possível fator de relevância possuir um bom restaurante, pois 31 dos respondentes gostariam de comer bem no local.

\section{CONSIDERAÇÕES FINAIS}

O problema que pretendeu-se resolver com esta pesquisa foi: Qual a percepção da qualidade nos hotéis de Santa Maria, na visão dos clientes e na visão dos gestores? Destaca-se que ao final do trabalho as respostas a este problema foram alcançadas, visto que os resultados possibilitaram uma comparação entre o posicionamento dos clientes com o dos gestores, em relação a diferentes questões.

Já quanto ao objetivo do estudo, que foi entender a percepção da qualidade no setor hoteleiro de Santa Maria, RS, na visão dos clientes e na visão dos gestores, cabe ressaltar alguns pontos importantes. Nota-se que entre os gestores tudo é considerado importante, mas duas áreas se destacam, sendo uma academia de 
ginástica e um bom restaurante, já que 3 gestores concordam totalmente quanto a estes atrativos serem importantes.

A partir da análise dos dados, percebe-se também que os clientes e os gestores pensam de forma parecida quanto à percepção de qualidade. Entretanto, dois fatores se sobressaem nas divergências entre clientes e gestores: conforto e alimentação. No que tange ao conforto, os clientes dizem que os hotéis não se preocupam com o bem-estar dos clientes e os gestores entendem que têm esta preocupação. Já quanto à alimentação, os clientes consideram que esse não é um fator decisivo, enquanto que os gestores se preocupam muito com isso. Assim, é possível inferir que os gestores estão se preocupando com alguns fatores secundários, sem conhecer plenamente a expectativa dos seus clientes.

Cabe citar ainda, que a prestação de serviços é algo intangível, mas que reflete no retorno do cliente, isto é, as ações das pessoas interferem no serviço. Isso demonstra que o colaborador e a empresa devem estar em sintonia para evitar falhas e não perder o cliente. É importante ressaltar que um cliente insatisfeito repassa a 25 indivíduos sua insatisfação com a prestação de serviços (KOTLER; KELLER, 2006), o que aumenta a probabilidade do seu serviço ser cada vez mais difamado, ocasionando perda de clientes e futuros clientes que poderiam vir a buscar seus serviços.

A pesquisa apontou que o principal fator decisivo para o cliente retornar ao hotel é o conforto oferecido nos quartos, e o gestor não percebe essa situação, uma vez que considera alimentação e tecnologia tão importantes quanto o fator conforto. Portanto, percebe-se diferenças que devem ser levadas em consideração nas opiniões dos clientes e dos gestores. A qualidade para esses dois públicos é parecida, mas o gestor considera tudo importante e não parece refletir sobre aquilo que realmente irá impactar na escolha dos clientes.

Considera-se, então, que o estudo conseguiu alcançar plenamente seu objetivo geral, que era entender a percepção da qualidade no setor hoteleiro de Santa Maria, RS, na visão dos clientes e na visão dos gestores. Por fim, como sugestões para futuras pesquisas, sugere-se a aplicação de uma pesquisa com os colaboradores dos hotéis, no que tange à qualidade de vida no ambiente de trabalho. Ainda, seria interessante pesquisar sobre a utilização de ferramentas estratégicas utilizadas na gestão da empresa, como o planejamento estratégico, a fim de alinhar os resultados desta pesquisa com o planejamento de ações para melhoria da qualidade.

\section{REFERÊNCIAS}

ABIH - Associação Brasileira da Indústria Hoteleira. Apresenta os serviços oferecidos. Disponível em http://www.abih.com.br/site.php. Acesso em: 7 ago. 2007.

ALMEIDA, S. Ah! Eu Não Acredito: como cativar o cliente através de um fantástico atendimento. 86. ed. Salvador: Casa da Qualidade, 2001.

DEFEO, J. A.; JURAN, J. M. Fundamentos da qualidade para líderes. Porto Alegre: Bookman. 2015.

GIANESI, I. G. N.; CORRÊA, H. L. Administração Estratégica de Serviços: operações para a satisfação de clientes. São Paulo: Atlas, 2006. 233 p.

GIL, A. C. Método e técnicas de pesquisa social. 6. ed. São Paulo: Atlas, 2008. 
GORINI, A. P. F.; MENDES, E. F. Setor de turismo no Brasil: segmento de hotelaria. BNDES Setorial. Rio de Janeiro, n. 22, set. 2005, p. 111-150. Disponível em: http://web.bndes.gov.br/bib/jspui/handle/1408/2188. Acesso em: 1 jun. 2007.

GRAY, C. Entrepreneurship, resistance do change and growth in small firms. Journal of Small Business and Enterprise Development, v. 9, n. 1, p. 61-72, 2002.

IBGE. Pesquisa Anual de Serviços, Rio de Janeiro, v. 4, 2002. ISSN - 1519-8006. Disponível em: https://biblioteca.ibge.gov.br/visualizacao/periodicos/150/pas_2002_v4.pdf. Acesso em: 3 mar. 2007.

KOTLER, P.; KELLER, K. L. Administração de Marketing. 12. ed. São Paulo: Pearson Prentice Hall, 2006. $750 \mathrm{p}$.

LICKFELD, W. A Qualidade como Fator de Revitalização dos Empreendimentos Hoteleiros de Blumenau. Turismo: Visão e Ação, Itajaí, v. 3, n. 6, p. 69-84, abr./set. 2000.

LOVELOCK, C.; GUMMESSON, E. Wheither Services Marketing?: In Search of a New Paradigm and Fresh Perspectives. Journal of Service Research, v. 7, n. 1, p. 20-41, ago. 2004.

MARCONI, M. A.; LAKATOS, E. M. Técnicas de Pesquisa. 7. ed. São Paulo: Atlas; 2007.

MARQUES, J. A. Introdução à hotelaria. Bauru: EDUSC, 2003.

MORRISON, A.; THOMAS, R. The future of small firms ins the hospitality industry. International Journal of Contemporary Hospitality Management, v. 11, n. 4, p. 148-154, 1999.

PALADINI, E. P. Perspectiva estratégica da qualidade. In. CARVALHO M. M. de; PALADINI, E. P. Gestão da qualidade: teorias e casos. 2. ed. Rio de Janeiro: ABEPRO, 2012.

PARASURAMAN, A.; ZEITHAML, V. A.; BERRY, L. L. A Conceptual Model of Service Quality and Its Implications for Future Research. Journal of Marketing, v. 49, p. 41 - 50, 1985.

SEBRAE. Princípios da Qualidade. 2 ed. Porto Alegre: SEBRAE, 2000. v. I.

SERSON, F. Hotelaria: a busca da excelência. São Paulo: Marcos Cobra, 2000.

SOUZA, E. C. L.; CASTRO-LUCAS, C. Cultura e Atitude Empreendedora: um Estudo em Empresas no Distrito Federal. Faces, v. 6, p. 10-25, 2007.

TINOCO, M. A. Proposta de modelos de satisfação dos consumidores de serviços. 2006. Dissertação (Mestrado em Engenharia de Produção) - Universidade Federal do Rio Grande do Sul, 2006. 